\title{
Adrenergic Regulation of Blood Pressure in Chronic Renal Failure
}

\author{
John J. Lilley, Joel Golden, and Richard A. Stone \\ From the Division of Nephrology, Department of Medicine, University of \\ California, San Diego, School of Medicine, and Veterans Administration \\ Hospital, San Diego, California 92161
}

\begin{abstract}
A B S T R A C T Previous investigations have suggested that significant hypotension during hemodialysis may result from abnormalities of sympathetic nervous system activity. To further evaluate these phenomena, plasma dopamine $\beta$-hydroxylase $(\mathrm{D} \beta \mathrm{H})$ and cold pressor test (proposed indexes of efferent sympathetic nervous system activity) and amyl nitrite inhalation (an index of the entire baroreceptor reflex arc) were studied in two groups of patients: group I, patients exhibiting a mean arterial pressure decrease to less than $70 \mathrm{~mm} \mathrm{Hg}$ during less than $10 \%$ of dialyses; group II (hemodialysis hypotension), patients with a mean arterial pressure decrease to less than $70 \mathrm{~mm} \mathrm{Hg}$ during more than $90 \%$ of dialyses. The groups were similar with respect to plasma renin activity, renin response to ultrafiltration, age, duration of dialysis, nerve conduction velocity, plasma protein concentration, hematocrit, dialysis weight change, resting heart rate, sex, race, blood pressure and heart rate response to cold pressor test, and ${ }^{125} \mathrm{I}$-albumin plasma volume. Supine mean arterial pressure was higher in patients with hemodialysis hypotension than in patients without hemodialysis hypotension (group I) both before and after dialysis. Plasma $\mathrm{D} \beta \mathrm{H}$ activity was significantly higher in patients with hemodialysis hypotension (group II) than in group I both before and after dialysis. Amyl nitrite inhalation, expressed as change in $\Delta \mathrm{R}-\mathrm{R}$ interval/mean arterial pressure decrease, was less in hemodialysis hypotension patients.

These results suggest that hemodialysis hypotension may result from a lesion in the baroreceptors, cardiopulmonary receptors, or visceral afferent nerves. Furthermore, elevated mean arterial pressure in patients with hemodialysis hypotension may be neurogenic in origin, as reflected by plasma $\mathrm{D} \beta \mathrm{H}$ activity, and appears similar to the hypertension that follows baroreceptor deafferentation of experimental animals.
\end{abstract}

Received for publication 2 October 1975 and in revised form 29 December 1975.

\section{INTRODUCTION}

Many previous studies of systemic blood pressure regulation in patients with chronic renal disease have emphasized the importance of plasma volume and the reninangiotensin system (1-4). Investigations of the sympathetic nervous system are limited and have either failed to localize an autonomic lesion or neglected any possible relationship of the aforementioned defect with clinical behavior on hemodialysis (5-9). The results of two investigations suggest that severe hypotension during hemodialysis may be related to autonomic neuropathy, reduction in central blood volume, or lower plasma oncotic pressure $(5,7)$. There was no obvious localization of the autonomic defect and no description of blood pressure patterns before and after hemodialysis treatment. Other groups have reported a baroreceptor defect in all hemodialysis patients but failed to relate this proposed abnormality to blood pressure regulation during dialysis and the interdialytic interval $(6,9)$. In the present investigation of a well-defined group of chronic renal failure patients, we have attempted to further localize an autonomic nervous system defect and to relate this abnormality to blood pressure patterns before, during, and after hemodialysis. Additionally, we have attempted to relate our observations to measurements of plasma volume and the renin-angiotensin system.

A proposed defect of autonomic function may be investigated by observing the hemodynamic responses to various physiologic or pharmacologic manipulations. Inhalation of amyl nitrite appears to be a useful way to determine the function of the visceral afferent and efferent limbs of the cardiopulmonary or baroreceptor reflex arcs (5). The early hemodynamic response to immersion of one hand in ice water (cold pressor test) is a proposed index of visceral efferent adrenergic activity or vascular integrity (10). Thus, the combination of amyl nitrite inhalation and a cold pressor test would 
appear to allow localization of a physiologic defect to either the afferent or efferent limb of the autonomic nervous system.

The measurement of dopamine $\beta$-hydroxylase $(\mathrm{D} \beta \mathrm{H})^{1}$ in plasma appears to be a useful biochemical tool for the investigation of adrenergic function $(11,12) . \mathrm{D} \beta \mathrm{H}$ is the enzyme that catalyzes the conversion of dopamine to norepinephrine and coexists with norepinephrine in the presynaptic vesicles of sympathetic neurons (13). Neurogenic discharge is associated with the release of norepinephrine via the process of exocytosis and is accompanied by the simultaneous release of the soluble portion of $\mathrm{D} \beta \mathrm{H}$ (14). The enzyme has no known route of excretion and appears to have a much longer biological half-life than catecholamines (15). Therefore, it has been proposed that plasma $\mathrm{D} \beta \mathrm{H}$ activity may provide an index of adrenergic function (12). The enzyme was measured before and after hemodialysis in all our patients.

\section{METHODS}

Patients. The subjects of this study were patients with chronic renal failure who were being treated with repetitive maintenance hemodialysis at the Veterans Administration and University Hospitals of San Diego and the Biomedical Corporation of San Diego. Diabetes mellitus was excluded in all patients by clinical history, glucose tolerance tests, and funduscopic examination. All patients were evaluated for severe hemodialysis hypotension (arbitrarily defined as a decrease of mean arterial pressure to less than 70 $\mathrm{mm} \mathrm{Hg}$ ) for at least $2 \mathrm{mo}$. Although measurements were performed at least one time each hour in all patients, occasional multiple pressures were taken and these were averaged for purposes of group classification, and only subjects who fulfilled the arbitrary criteria listed below were included: group I, patients who exhibited a decrease of mean arterial pressure to less than $70 \mathrm{~mm} \mathrm{Hg}$ during less than $10 \%$ of hemodialyses; group II, patients who manifested a decrease of mean arterial pressure to less than $70 \mathrm{~mm} \mathrm{Hg}$ at least one time during at least $90 \%$ of hemodialyses. Patients who exhibited a blood pressure increase associated with hemodialysis were not included. All patients exhibited their usual blood pressure patterns on the days of investigation.

All patients were studied on a day when their predialysis weight did not exceed their predicted "dry" weight (arbitrarily defined as an edema-free state with less than a $12 \mathrm{~mm}$ $\mathrm{Hg}$ decrease in systolic blood pressure after rising from supine to standing) by more than $3 \mathrm{~kg}$. All forms of antihypertensive medications were discontinued for at least 8 wk before study. Both groups continued their usual dietary prescriptions-a high biologic value diet containing approximately $2 \mathrm{~g}$ of sodium per $24 \mathrm{~h}$. All patients participated in their usual ambulatory activities before testing; none were hospitalized for the purpose of these studies. All patients gave their informed written consent, and the Committee on Human Experimentation of the University of California, San Diego, approved the protocol.

Procedures. Blood pressure measurements (arm cuff method) were performed by one of the investigators (J. L.

${ }^{1}$ Abbreviations used in this paper: $\mathrm{D} \beta \mathrm{H}$, dopamine $\beta$ hydroxylase; MAP, mean arterial pressure; PRA, plasma renin activity. or J. G.) before and after hemodialysis, using a mercury manometer. The recorded blood pressures (pre- and postdialysis) represent the average of two separate determinations in each position. For purposes of group classification, blood pressures and heart rates were monitored before, during, and after dialysis for at least 2 mo before testing. No patient was included who did not meet our criteria (vide supra). Pre- and post-dialysis heart rates were determined by cardiac auscultation. Each patient was kept supine, in the bed used during dialysis, for $15 \mathrm{~min}$ before the treatment. At the end of that time interval blood pressure (by the arm cuff method) and pulse (by auscultation) were determined. The patient was then asked to stand and the measurements were repeated after 2 min of upright posture. This same sequence of events and measurements was repeated after dialysis had been terminated (with return of all extracorporeal volume). Blood pressures are recorded or arbitrarily expressed as mean arterial pressure (diastolic pressure $+1 / 3$ pulse pressure ; MAP).

Venous blood samples were obtained for peripheral venous plasma renin activity (PRA), plasma $\mathrm{D} \beta \mathrm{H}$ activity, serum electrolyte concentration, plasma protein concentration, and hematocrit while the patient remained in the supine position. All samples were obtained without a tourniquet from the standard fistula needle at a time at which there was no extracorporeal blood. Peripheral blood samples were collected in chilled vacuum tubes containing either EDTA (PRA) or heparin $(\mathrm{D} \beta \mathrm{H})$. The blood to be assayed for $\mathrm{D} \beta \mathrm{H}$ or PRA was placed on ice, separated in a refrigerated centrifuge $\left(4^{\circ} \mathrm{C}\right)$, and stored at $-20^{\circ} \mathrm{C}$ for subsequent assay. All predialysis and postdialysis measurements were obtained at 7-8 a.m. and at 2-3 p.m., respectively.

Cold pressor testing was performed on the 10 subjects (five from each group) at the Veterans Administration Hospital in the semirecumbent posture at the termination of dialysis while the subjects were at "dry" weight (vide supra) and after blood in the dialysis machine had been returned to the patient. The test was performed by immersion of one hand in ice water for $1 \mathrm{~min}(10,16)$.

An amyl nitrite inhalation test was performed after the cold pressor test on the same 10 subjects, five patients from each group (those at the Veterans Administration Hospital). While the patient maintained a semirecumbent position, a gas-filled ampoule of amyl nitrite was broken under the nose and the patient inhaled deeply three times.

During both the cold pressor test and amyl nitrite inhalation, arterial pressures were measured directly through a percutaneously introduced, short, Teflon cannula, inserted into either the radial or brachial artery of the arm opposite to that containing the arteriovenous access site. The cannula was the coupled to a Hewlett-Packard $1280 \mathrm{C}$ pressure transducer connected to a Hewlett-Packard $8805 \mathrm{C}$ pressure amplifier and a Hewlett-Packard 7754A hot-stylus, stripchart recorder (Hewlett-Packard Co., Palo Alto, Calif.). A simultaneous electrocardiographic tracing was obtained with a 8811B Hewlett-Packard ECG amplifier. Maximum and minimum changes in pulse interval ( $R-R$ interval) were then determined from the tracings and related to the systolic pressure of the immediately preceding cardiac cycle (17).

Supine plasma volume determinations by the method of radioiodine-labeled serum albumin were performed on five patients in each group (those at the Veterans Administration Hospital). In each patient the blood background count was measured and the injected dose was increased to exceed the background count in the blood appropriately by a factor of four. The radioiodinated human serum albumin was in- 
jected intravenously, and plasma samples were obtained at 10 and $20 \mathrm{~min}$ after injection. This procedure was accomplished before hemodialysis and after hemodialysis after all extracorporeal blood had been returned to the patient.

All patients were dialyzed with Gambro Lundia Nova (AB Gambro, Lund, Sweden) $13.5-\mu \mathrm{m}$ parallel plate dialyzers with blood flows of $175-225 \mathrm{ml} / \mathrm{min}$. Weight change during dialysis was measured in all patients with a standard Brookline bed scale. Motor and sensory nerve conduction velocities were performed on all patients within 2 mo of other investigations. This procedure was accomplished by application of a stimulus at two or more points on the median, ulnar, and peroneal nerves with a monopolar stimulating electrode; the cathode was placed on the nerves and recording electrodes positioned on the innervated muscles.

Chemical. PRA was measured with the method of Haber et al. (18) via the radioimmunoassay of generated angiotensin I after $1 \mathrm{~h}$ of incubation at $\mathrm{pH}$ 5.5. The reagents for the assay were purchased from New England Nuclear, Boston, Mass. Both incubations and immunoassays were performed in duplicate resulting in four values of generated angiotensin I per plasma sample. All values were required to fall within $\pm 15 \%$ of the mean of the four analyses. The reproducibility of the method was determined by replicate analysis on single samples $(n=20)$ with "high" and "low" PRA. The interassay coefficients of variation (expressed as $1 \mathrm{SD} / \mathrm{mean}$ ) were 12 and $14.6 \%$ for the "high" and "low" samples, respectively. All results are expressed as nanograms of angiotensin I generated per milliliter per hour.

Analysis of plasma $\mathrm{D} \beta \mathrm{H}$ activity was performed according to the method of Nagatsu and Udenfriend (19). All assays were performed in duplicate on $50 \mu \mathrm{l}$ of plasma and the results of the two individual measurements were required to fall within $\pm 2 \mathrm{U}$ of the mean of the two analyses. The reproducibility of the method was determined by replicate analysis on a single sample $(n=40)$. The interassay coefficient of variation was $4.5 \%$. The use of $N$-ethylmaleimide served as an effective means of inactivating possible endogenous inhibitors as previously described (20). All results are expressed as International Units (micromoles/minute)/ liter plasma at $37^{\circ} \mathrm{C}$; micromoles octopamine formed (units/ liter). Other tests were performed in the routine hospital laboratories.

Statistics. Student's $t$ test and simple and multiple linear regression analyses were performed utilizing statistical techniques (21). All values are expressed as a mean \pm SEM unless otherwise stated.

\section{RESULTS}

Although individuals exhibited variability of time and frequency of hypotensive episodes, 20 patients (10 in each group) fulfilled our arbitrary selection criteria (vide supra). Representative hemodialysis blood pressure patterns from one patient in each group are displayed (Fig. 1).

Patients in both groups were similar with respect to age, sex, race, renal diagnosis, and duration of hemodialysis treatment (Table I). The average age of the 10 patients in group I was $46 \mathrm{yr}$ (range, 25-59 yr) and did not differ $(P>0.90)$ from the 10 patients in group II, who ranged in age from 24 to $62 \mathrm{yr}$ (mean, $49 \pm 3.6$ yr). The mean duration of chronic hemodialysis was

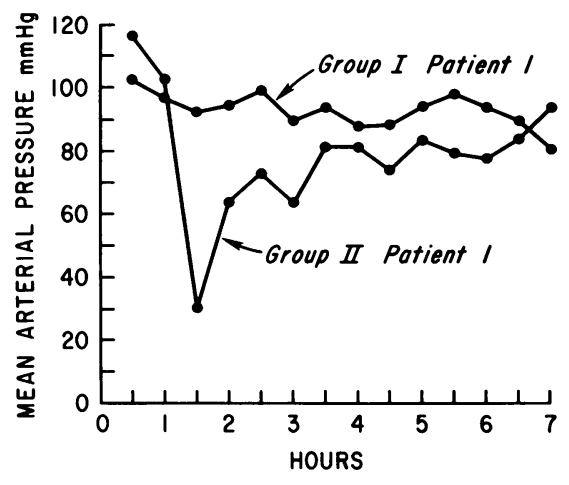

FIgURE 1 Representative hemodynamic changes during a single hemodialysis in one patient from each group. Note the marked drop in mean arterial pressure occurring $1 \frac{1}{2} \mathrm{~h}$ into dialysis in the patient from group II. Other patients exhibited similar blood pressure patterns, but the time-course of the hypotensive episodes varied between patients.

\section{$24.4 \pm 4.8 \mathrm{mo}$ in group I and averaged $16.6 \pm 3.3 \mathrm{mo}$ in} group II $(P>0.20)$.

Supine MAP was significantly higher in group II patients before and after hemodialysis (Table I). The higher MAP in group II appeared to result primarily from systolic blood pressures which were significantly higher $(P<0.05)$ in group I than in group II (as opposed to the diastolic pressures, which were not $[P>$ 0.05 ) (Fig. 2). The average supine predialysis auscultatory heart rate was $88 \pm 6$ beats/min in group I and was similar $(P>0.05)$ to the rate of $85 \pm 7$ beats $/ \mathrm{min}$ in group II. The mean supine postdialysis heart rate of $84 \pm 5$ beats $/ \mathrm{min}$ in group I did not differ $(P>0.05)$ from the $83 \pm 7$ beats $/ \mathrm{min}$ observed in group II. The

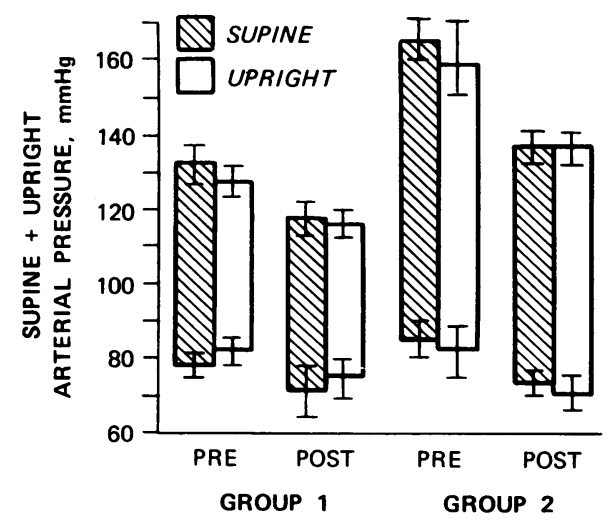

FIGURE 2 Effect of hemodialysis on arterial blood pressure in patients without hemodialysis hypatension (group I) and with hemodialysis hypotension (group II). Each paired column represents an average of systolic and diastolic pressures, taken before and after dialysis, in the supine and upright position (expressed as mean \pm SEM). Supine and upright systolic pressure are significantly different $(P<$ 0.05 ) between groups I and II both before and after dialysis. 


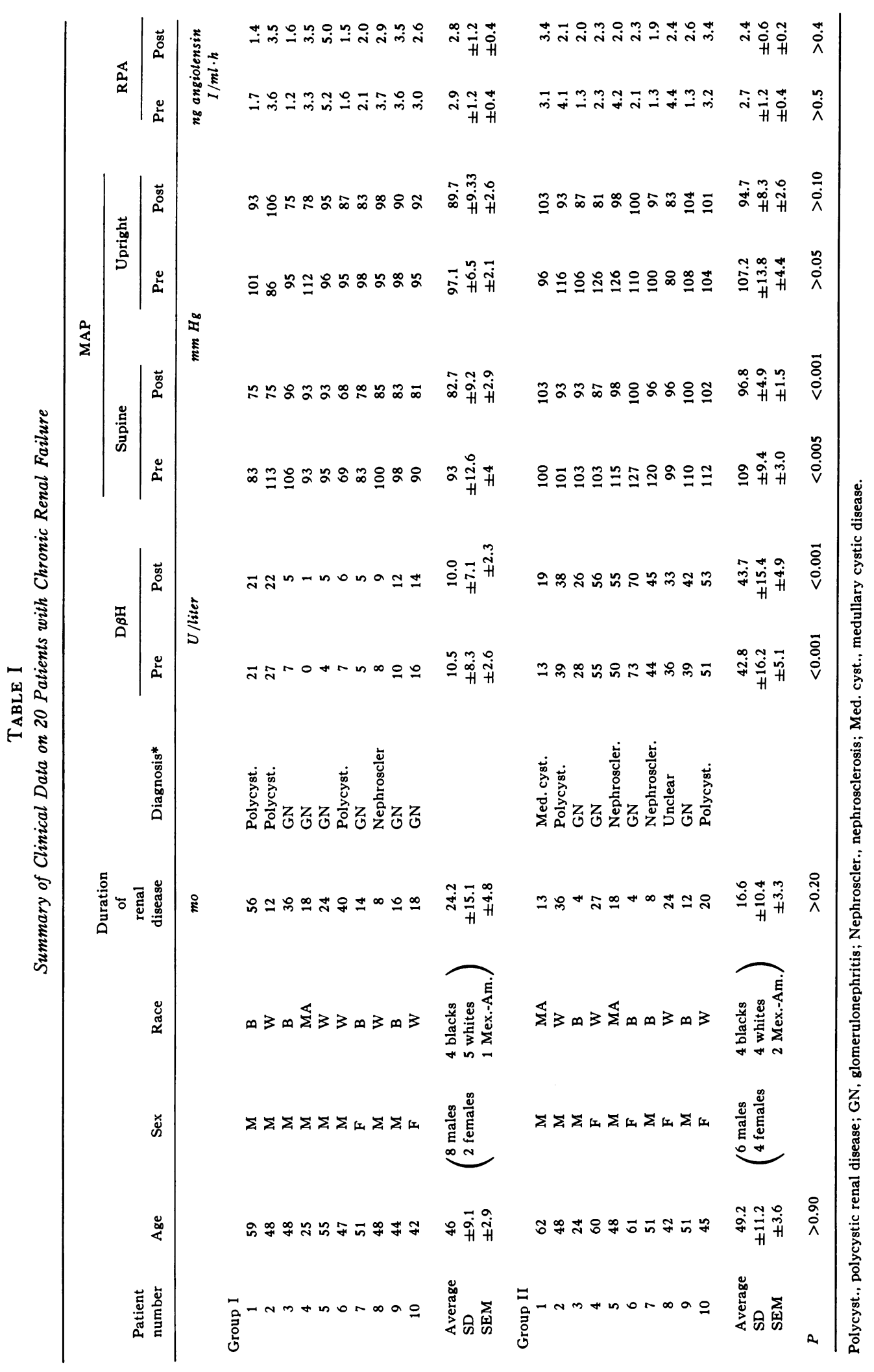

Adrenergic Dysfunction in Chronic Renal Failure 
average upright heart rate before dialysis was $86 \pm 7$ beats $/ \mathrm{min}$ in group I and was similar $(P>0.05)$ to the rate of $87 \pm 5$ beats/min in group II patients. The mean upright postdialysis heart rate in group I subjects was $87 \pm 6$ beats $/ \mathrm{min}$ and did not differ $(P>0.05)$ from the $85 \pm 6$ beats/min observed in group II.

The hemodynamic responses to the cold pressor test did not differ between the two groups (Table II). Patients in group I exhibited a maximum increase in MAP which averaged $19 \pm 5 \mathrm{~mm} \mathrm{Hg}$ and a mean maximum decrement of R-R interval of $48 \pm 10 \mathrm{~ms}$. Group II subjects showed a maximum MAP increment of $21 \pm 5 \mathrm{~mm}$ $\mathrm{Hg}$ and a maximum $\mathrm{R}-\mathrm{R}$ interval decrement which averaged $66 \pm 21 \mathrm{~ms}$. Neither of these hemodynamic alterations was significantly different between the groups $(P>0.05)$ during any interval of the maneuver.

Amyl nitrite inhalation in the group I patients stud-

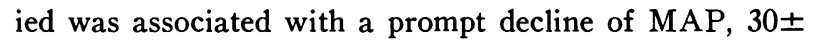
$5.0 \mathrm{~mm} \mathrm{Hg}$, and was accompanied by a decrement in $\mathrm{R}-\mathrm{R}$ interval, $152.6 \pm 32.5 \mathrm{~ms}$ (Table III). Group II patients exhibited a similar change in MAP, $33.6 \pm 5.5$ $\mathrm{mm} \mathrm{Hg}(P>0.05)$; however, the decrement in R-R interval was significantly less, $36.2 \pm 5.9 \mathrm{~ms} \quad(P<.01)$. The conventional ratio of change in $R-R$ interval/change in MAP averaged $5.1 \pm 0.7$ for group I and was significantly higher $(P<.001)$ than the observed ratio of $1.18 \pm 0.26$ in group II (Table III).
Radioiodinated plasma volumes (standardized for body surface area) were similar in the patients studied before hemodialysis treatment (Table IV). However, patients in group II exhibited significantly lower volumes after dialysis $(P<0.01)$ despite their higher observed MAP and systolic blood pressures.

Sensory nerve conduction velocities on all patients in group I averaged $3.1 \pm 0.68 \mathrm{~m} / \mathrm{s}$ and $2.4 \pm 0.53 \mathrm{~m} / \mathrm{s}$ for the median and ulnar nerves, respectively. Patients in group II exhibited sensory nerve condition velocities which averaged $3.5 \pm 0.3 \mathrm{~m} / \mathrm{s}$ for the median nerve and $3.1 \pm 0.16 \mathrm{~m} / \mathrm{s}$ for the ulnar nerve. These measurements were similar to those observed in group I patients $(P>$ 0.05 ). Median, ulnar, and peroneal motor nerve conduction velocities were $51.1 \pm 3.3,51.4 \pm 3.8$, and $42.1 \pm 4.1$ $\mathrm{m} / \mathrm{s}$, respectively, in group I subjects. Group II motor nerve conduction velocities for the median, ulnar, and peroneal nerves were $48.3 \pm 1.7,46.1 \pm 2.8$, and $40.5 \pm 1.3$ $\mathrm{m} / \mathrm{s}$, respectively. All these measurements were similar $(P>0.05)$ in both study groups, but these results differ from those of Kersh et al. (5), who observed depressed conduction velocities only in patients with autonomic abnormalities.

The average weight decrease associated with hemodialysis in group I on the day of investigation was $1.3 \pm 0.4 \mathrm{~kg}$ and was similar to subjects in group II $(P>$ 0.05 ), who exhibited an average weight decrement of

TABLE II

Hemodynamic Changes with Cold Pressor Test

\begin{tabular}{|c|c|c|c|c|c|c|c|}
\hline \multirow{2}{*}{$\begin{array}{l}\text { Patient } \\
\text { number }\end{array}$} & \multicolumn{3}{|c|}{ MAP (semirecumbent) } & \multicolumn{3}{|c|}{$\mathbf{R}-\mathbf{R}$} & \multirow{2}{*}{$\frac{\Delta \mathrm{R}-\mathrm{R}}{\Delta \mathrm{MAP}}$} \\
\hline & Control & Maximum & $\Delta$ & Control & Minimum & $\Delta$ & \\
\hline & \multicolumn{3}{|c|}{$m m \mathrm{Hg}$} & \multicolumn{3}{|c|}{$m s$} & $\mathrm{~ms} / \mathrm{mm} \mathrm{Hg}$ \\
\hline \multicolumn{8}{|l|}{ Group I } \\
\hline 1 & 80 & 91 & 11 & 700 & 660 & 40 & 3.63 \\
\hline 2 & 81 & 117 & 36 & 600 & 540 & 60 & 1.67 \\
\hline 3 & 114 & 140 & 26 & 620 & 600 & 20 & 0.77 \\
\hline 4 & 93 & 107 & 14 & 800 & 720 & 80 & 5.71 \\
\hline 5 & 96 & 106 & 10 & 700 & 660 & 40 & 4.0 \\
\hline Average & 92.8 & 112.2 & 19.4 & 684 & 636 & 48 & 3.15 \\
\hline SD & \pm 13.8 & \pm 18.1 & \pm 11.2 & \pm 79.3 & \pm 68.4 & \pm 22.8 & \pm 1.96 \\
\hline SEM & \pm 6.2 & \pm 8.1 & \pm 5.0 & \pm 35.4 & \pm 30.6 & \pm 10.2 & \pm 0.9 \\
\hline \multicolumn{8}{|l|}{ Group II } \\
\hline 1 & 100 & 117 & 17 & 840 & 760 & 80 & 4.71 \\
\hline 2 & 75 & 91 & 16 & 560 & 510 & 50 & 3.13 \\
\hline 3 & 102 & 113 & 11 & 860 & 720 & 140 & 12.72 \\
\hline 4 & 94 & 131 & 37 & 620 & 580 & 40 & 1.08 \\
\hline 5 & 98 & 123 & 25 & 720 & 700 & 20 & 0.80 \\
\hline Average & 93.8 & 115.0 & 21.2 & 720 & 654 & 66 & 4.49 \\
\hline SD & \pm 10.9 & \pm 15.0 & \pm 10.2 & \pm 131.9 & \pm 104.8 & \pm 46.7 & \pm 4.9 \\
\hline SEM & \pm 4.9 & \pm 6.7 & \pm 4.5 & \pm 59.0 & \pm 46.9 & \pm 20.9 & \pm 2.2 \\
\hline$P$ & $>0.90$ & $>0.80$ & $>0.70$ & $>0.50$ & $>0.70$ & $>0.40$ & $>0.60$ \\
\hline
\end{tabular}


TABLE III

Hemodynamic Changes with Amyl Nitrite Inhalation

\begin{tabular}{cccc}
\hline $\begin{array}{c}\text { Patient } \\
\text { number }\end{array}$ & $\begin{array}{c}\Delta \\
\text { MAP }\end{array}$ & $\begin{array}{c}\Delta \\
\mathrm{R}-\mathrm{R}\end{array}$ & $\frac{\Delta \mathrm{R}-\mathrm{R}}{\Delta \mathrm{MAP}}$ \\
\hline & $m m \mathrm{Hg}$ & $m s$ & $m s / m m \mathrm{Hg}$ \\
Group I & & & \\
1 & 13 & 60 & 4.62 \\
2 & 30 & 130 & 4.33 \\
3 & 44 & 220 & 5.0 \\
4 & 30 & 233 & 7.76 \\
5 & 33 & 120 & 3.63 \\
Average & 30 & 152.6 & 5.07 \\
SD & \pm 11.1 & \pm 72.7 & \pm 1.6 \\
SEM & \pm 5.0 & \pm 32.5 & \pm 0.7 \\
Group II & & & \\
1 & 53 & 27 & 0.51 \\
2 & 21 & 20 & 0.95 \\
3 & 26 & 54 & 2.08 \\
4 & 36 & 40 & 1.11 \\
5 & 32 & 40 & 1.25 \\
Average & 33.6 & 36.2 & 1.18 \\
SD & \pm 12.2 & \pm 13.2 & \pm 0.58 \\
SEM & \pm 5.5 & \pm 5.9 & \pm 0.26 \\
$P$ & $>0.30$ & $<0.01$ & $<0.001$ \\
\hline
\end{tabular}

$1.6 \pm 0.3 \mathrm{~kg}$. Plasma protein concentrations in group I before and after hemodialysis measured $7.7 \pm 0.3$ and $8.0 \pm 0.3 \mathrm{~g} / 100 \mathrm{ml}$, respectively, and did not differ $(P>$ 0.05 ) from patients in group II, who exhibited plasma protein concentrations of $7.8 \pm 0.2 \mathrm{gm} / 100 \mathrm{ml}$ before dialysis and $7.9 \pm 0.3 \mathrm{~g} / 100 \mathrm{ml}$ after dialysis.

Patients in group I exhibited a mean predialysis serum sodium concentration of $136 \pm 0.7 \mathrm{meq} / \mathrm{liter}$ and an average predialysis serum potassium concentration of $6.1 \pm 0.4 \mathrm{meq} /$ liter. These measurements were similar $(P>0.05)$ to the observed predialysis $138 \pm 0.9 \mathrm{meq} /$ liter for serum sodium concentration and $5.8 \pm 0.6 \mathrm{meq} /$ liter for serum potassium concentration in group II. Postdialysis serum sodium and potassium concentrations averaged $139 \pm 0.4$ and $4.5 \pm 0.2 \mathrm{meq} / \mathrm{liter}$, respectively, for group I and did not differ $(P>0.05)$ from patients in group II, who averaged $138 \pm 0.3$ and $4.4 \pm 0.4 \mathrm{meq} /$ liter for serum sodium and potassium concentrations, respectively. The mean peripheral venous hematocrit in group I was $22 \pm 0.2 \%$ before dialysis and $24 \pm 0.2 \%$ after dialysis. Predialysis and postdialysis peripheral venous hematocrits averaged $21 \pm 0.4$ and $22 \pm 0.4 \%$, respectively in group II and were similar to those in group I $(P>0.05)$.

Predialysis supine PRA ranged between 1.2 and 5.2

TABLE IV

Volume Measurements

\begin{tabular}{|c|c|c|c|c|c|c|c|}
\hline \multirow{2}{*}{$\begin{array}{l}\text { Patient } \\
\text { number }\end{array}$} & \multicolumn{2}{|c|}{ Observed plasma volume } & \multicolumn{2}{|c|}{ Predicted* plasma volume } & \multirow[b]{2}{*}{ BSAt } & \multicolumn{2}{|c|}{ Plasma volume/BSA } \\
\hline & Pre & Post & Pre & Post & & Pre & Post \\
\hline & \multicolumn{2}{|c|}{$m l$} & \multicolumn{2}{|c|}{$m l$} & $m^{2}$ & \multicolumn{2}{|c|}{$m l / m^{2}$} \\
\hline Group I & & & & & & & \\
\hline 1 & 5,179 & 5,108 & 3,875 & 3,820 & 2.25 & 2,301 & 2,270 \\
\hline 2 & 4,028 & 4,824 & 3,372 & 3,371 & 2.06 & 1,955 & 2,341 \\
\hline 3 & 4,677 & 4,628 & 4,016 & 4,000 & 2.29 & 2,042 & 2,020 \\
\hline 4 & 4,815 & 4,570 & 2,875 & 2,812 & 1.69 & 2,849 & 2,704 \\
\hline 5 & 6,434 & 5,113 & 2,935 & 2,917 & 1.86 & 3,459 & 2,748 \\
\hline Average & 5,047 & 4,849 & 3,415 & 3,384 & 2.03 & 2,521 & 2,457 \\
\hline $\mathrm{SD}$ & \pm 885 & \pm 257 & \pm 524 & \pm 528 & \pm 0.26 & \pm 630 & \pm 308 \\
\hline SEM & \pm 396 & \pm 115 & \pm 234 & \pm 236 & \pm 0.11 & \pm 282 & \pm 138 \\
\hline \multicolumn{8}{|l|}{ Group II } \\
\hline 1 & 3,019 & 2,953 & 3,606 & 3,552 & 1.49 & 2,026 & 1,981 \\
\hline 2 & 3,242 & 3,565 & 2,967 & 2,906 & 1.88 & 1,724 & 1,896 \\
\hline 3 & 3,797 & 2,850 & 3,270 & 3,186 & 2.05 & 1,852 & 1,390 \\
\hline 4 & 3,122 & 3,053 & 1,950 & 1,968 & 1.53 & 2,040 & 1,995 \\
\hline 5 & 5,121 & 3,705 & 3,510 & 3,380 & 2.11 & 2,427 & 1,755 \\
\hline Average & 3,660 & 3,225 & 3,061 & 2,998 & 1.88 & 2,014 & 1,803 \\
\hline SD & \pm 870 & \pm 384 & \pm 668 & \pm 624 & \pm 0.30 & \pm 265 & \pm 250 \\
\hline SEM & \pm 389 & \pm 172 & \pm 299 & \pm 279 & \pm 0.13 & \pm 119 & \pm 112 \\
\hline$P$ & $<0.05$ & $<0.0001$ & $>0.05$ & $>0.05$ & $>0.20$ & $>0.10$ & $<0.01$ \\
\hline
\end{tabular}

* Predicted from standard tables on the basis of height and weight.

$\ddagger$ Body surface area, calculated on the basis of height and postdialysis weight. 


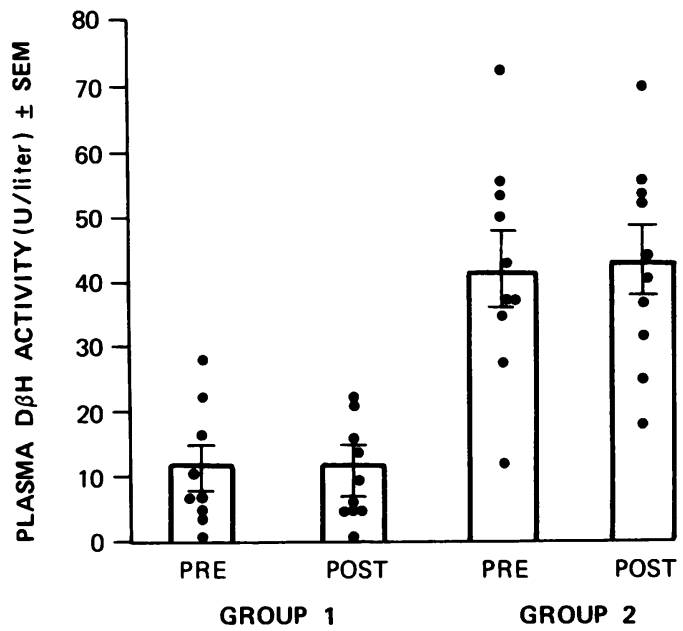

FIgURE 3 Activity of plasma $\mathrm{D} \beta \mathrm{H}$ in patients without hemodialysis hypotension (group I) and with hemodialysis hypotension (group II). Mean plasma $\mathrm{D} \beta \mathrm{H}$ is significantly greater in patients with hemodialysis hypotension both before and after dialysis. Vertical bars represent the mean, and brackets represent $\pm \mathrm{SEM} \quad(n=10$ in both patient groups).

$\mathrm{ng} / \mathrm{ml}$ and was similar after dialysis in group I $(P>$ 0.05) (Table I). Group II patients exhibited values for supine predialysis PRA which ranged from 1.3 to 4.4 $\mathrm{ng} / \mathrm{ml}$ and did not differ from postdialysis measurements $(P>0.05)$. Furthermore, PRA measurements before and after hemodialysis did not differ between the two groups $(P>0.05)$ (Table $\mathrm{I})$.

Plasma $\mathrm{D} \beta \mathrm{H}$ activity in peripheral venous blood averaged $10.5 \mathrm{U} /$ liter before dialysis and $10.0 \mathrm{U} /$ liter after dialysis in group I (Table I, Fig. 3).
In an attempt to determine the factor(s) controlling blood pressure, simple and multiple linear regression analyses were applied to supine and upright MAP versus $\mathrm{D} \beta \mathrm{H}, \mathrm{PRA}$, and volume measurements. Only those correlations which were significant are shown ( Table V).

\section{DISCUSSION}

To relate the present observations to dysfunction of the sympathetic nervous system, it is necessary first to review the physiologic tests performed and their proposed relationship to autonomic alterations. Inhalation of amyl nitrite appears to be a useful way to determine the integrity of the entire baroreceptor and cardiopulmonary reflex axis (5). Amyl nitrite results in peripheral vasodilatation with a concomitant decrease in blood pressure. This low-pressure stimulus decreases usual tonic inhibitory tone from visceral afferent fibers originating in the wall of the carotid arteries, atria, and other vascular structures (baroreceptors and cardiopulmonary receptors) and, through synapsis in the brain stem, increases efferent sympathetic activity $(22,23)$. This reflex arc may be modified by descending impulses from the cerebral cortex, brain stem, and hypothalamus (depressor and pressor areas). Reflex vasoconstriction and tachycardia are appropriate responses after amyl nitrite inhalation and a diminution of these phenomena suggests a defect in one or more components of the visceral autonomic reflex arc. Alternatively, a cold pressor test has been proposed as a valuable way to determine the integrity of the efferent limb of the sympathetic nervous system or the appropriate vascular receptors $(10,24)$. Although the cold pressor test is a complex stimulus in-

TABLE V

Correlation of Blood Pressure with PRA,D $B H$, and Volume*

\begin{tabular}{|c|c|c|c|c|c|c|}
\hline & \multicolumn{3}{|l|}{ Predialysis } & \multicolumn{3}{|l|}{ Postdialysis } \\
\hline & Correlation & $\begin{array}{l}\text { Correlation } \\
\text { coefficient }\end{array}$ & $P$ & Correlation & $\begin{array}{l}\text { Correlation } \\
\text { coefficient }\end{array}$ & $P$ \\
\hline Group I & $\begin{array}{l}\text { Supine MAP } \\
\text { MAP* vs. PRA + Volume } \\
\text { MAP vs. D } \beta H \S+\text { Volume + PRA }\end{array}$ & $\begin{array}{l}0.97 \\
0.99\end{array}$ & $\begin{array}{l}<0.01 \\
<0.001\end{array}$ & $\begin{array}{l}\text { Supine MAP } \\
\text { MAP vs. PRA + Volume } \\
\text { MAP vs. D } \beta H+\text { Volume + PRA }\end{array}$ & $\begin{array}{l}0.85 \\
0.98\end{array}$ & $\begin{array}{l}<0.05 \\
<0.01\end{array}$ \\
\hline Group II & $\begin{array}{l}\text { Supine MAP } \\
\text { MAP vs. Volume } \\
\text { MAP vs. D } \beta H+\text { Volume } \\
\text { MAP vs. D } \beta H+\text { Volume + PRA }\end{array}$ & $\begin{array}{l}0.85 \\
0.86 \\
0.86\end{array}$ & $\begin{array}{l}<0.05 \\
<0.05 \\
<0.05\end{array}$ & $\begin{array}{l}\text { Supine MAP } \\
\text { MAP vs. D } \beta \mathrm{H}+\text { Volume + PRA }\end{array}$ & 0.87 & $<0.05$ \\
\hline Group I & $\begin{array}{l}\text { Upright MAP } \\
\text { MAP vs. PRA + Volume } \\
\text { MAP vs. D } \boldsymbol{B H}+\text { Volume + PRA }\end{array}$ & $\begin{array}{l}0.89 \\
0.93\end{array}$ & $\begin{array}{l}<0.05 \\
<0.01\end{array}$ & $\begin{array}{l}\text { Upright MAP } \\
\text { MAP vs. D } \beta H+\text { PRA } \\
\text { MAP vs. } D \beta H+\text { Volume + PRA }\end{array}$ & $\begin{array}{l}0.99 \\
0.91\end{array}$ & $\begin{array}{l}<0.001 \\
<0.05\end{array}$ \\
\hline Group II & $\begin{array}{l}\text { Upright MAP } \\
\text { MAP vs. D } \beta H \\
\text { MAP vs. D } \beta H+\text { PRA }\end{array}$ & $\begin{array}{l}0.99 \\
0.87\end{array}$ & $\begin{array}{l}<0.001 \\
<0.05\end{array}$ & $\begin{array}{l}\text { Upright MAP } \\
\text { MAP vs. D } \beta H+\text { Volume + PRA }\end{array}$ & 0.86 & $<0.05$ \\
\hline
\end{tabular}

Simple and multiple regression analysis was applied to supine and upright mean arterial pressure versus D $B H$, PRA, and plasma volume. Only significant correlations are shown.

* Extracellular fluid volume per body surface area $\left(\mathrm{ml} / \mathrm{m}^{2}\right)$. 
volving somatic afferent neurons and the central nervous system, the early hemodynamic responses to this maneuver appear to reflect best the function of the efferent limb of the baroreceptor and cardiopulmonary reflex arcs. It should be cautioned that the initial blood pressure changes associated with this stimulus may alter later information transmitted by the visceral afferent autonomic nerves and effect subsequent circulatory changes. In summary, the hemodynamic sequelae following amyl nitrite inhalation and the early response to the cold pressor test appear to allow a physiological division of the visceral autonomic reflex arc into its afferent and efferent limbs. Neither hemodynamic maneuver allows one to assess the relative influences of pressor and depressor areas in the central nervous system.

Amyl nitrite inhalation and cold pressor test were performed in two groups of hemodialysis patients. Group I included subjects who rarely experienced hypotensive episodes with hemodialysis and group II consisted of patients who frequently have hemodialysis hypotension. Both groups of patients exhibited similar early hemodynamic responses to cold pressor tests, and these responses were similar to those previously observed in apparently healthy subjects $(16,25)$. Although conclusions from these results must be tempered by the aforementioned limitations of the cold pressor test, the data suggest that hemodialysis-associated hypotension does not result from defective efferent sympathetic nerves or vascular abnormalities. On the other hand, amyl nitrite inhalation was associated with significantly different responses between the two groups. Patients who frequently exhibited hemodialysis-associated hypotension also displayed diminished hemodynamic responses to amyl nitrite-induced hypotension. It is possible that although patients in group II experienced less tachycardia after amyl nitrite, their vasoconstrictor response was preserved or exaggerated. Since the decrement of MAP following amyl nitrite did not differ between the two groups, we feel that this is unlikely. It must be acknowledged also that differing central blood volumes may provide different stimuli to cardiopulmonary receptors and therefore result in individual alterations of response to amyl nitrite inhalation. Investigation of this issue would require measurements of central venous pressure, which involves a more invasive protocol than we have performed. It is also possible that the absence of a greater increase of arterial pressure during the cold pressor test in group II patients results from an associated baroreceptor defect or a peripheral autonomic neuropathy as suggested by Kersh et al. (5). However, it is more attractive to propose that the peripheral vessels are narrowed secondary to an increase of tonic adrenergic tone (as reflected by plasma $\mathrm{D} \beta \mathrm{H}$ activity), and that the vessels cannot constrict much more when the cold stimulus is applied. This latter proposal is more consistent with our data (vide infra). Thus, the present observations would appear to offer ample justification for suspecting that group II patients with hemodialysis hypotension exhibit a defect in the baroreceptors, the cardiopulmonary receptors, or the visceral afferent autonomic nerves. This proposed defect may be manifested clinically in two ways: $(a)$ an inability to elevate blood pressure acutely after the hypotensive stimulus imposed by hemodialysis; $(b)$ a loss of tonic inhibitory visceral afferent influence on the efferent adrenergic system contributing to hypertension during the interdialytic period (vide infra). We have not investigated any possible influence of higher vasoregulatory centers on these hemodynamic maneuvers $(26,27)$, and we have not determined the reasons for the observed different responses among groups of patients. There is no detectable relationship to age, sex, race, renal diagnosis, duration of hemodialysis, resting heart rate, serum electrolyte concentrations, plasma protein concentrations, peripheral nerve conduction velocity, or peripheral venous hematocrit in our patients. Furthermore, we have not eliminated the possibility that the observed changes resulted from differences in the duration of hypertension (27) or from the higher resting pressures exhibited by group II patients $(28,29)$. Answers to these latter two questions would require a more prospective evaluation than we have performed. It might also be proposed that the hemodialysis hypotension resulted from the smaller plasma volumes exhibited by this group, but this explanation is not consonant with the observation that most volumes in group II subjects were higher than predicted "normal" values. In addition, this possibility would not be consistent with the higher blood pressures found both before and after hemodialysis in these patients. The volume data might also explain the lack of postural hypotension after hemodialysis in group II patients. However, the orthostatic blood pressure results suggest to us that the stimulus of slow movement from supine to upright posture differs from the acute stress of hemodialysis or amyl nitrite inhalation. Tilt table orthostatic blood pressure measurements would provide a more adequate test of this hypothesis.

The results of previous studies of autonomic function in patients with chronic renal failure are limited and have yielded results which are difficult to compare with the present observations $(5,6,9)$. Kersh et al. (5) studied eight patients with hemodialysis hypotension and concluded that a generalized neuropathy was responsible for autonomic insufficiency in six of the patients and that adrenergic dysfunction resulted in a fall in total systemic resistence with fixed heart rate during the hemodialysis treatment. Further localization of the defect was not attempted and no blood pressures before and after dialy- 
sis were reported. Pickering et al. (6) and Lazarus et al. (9) have proposed that a baroreceptor defect exists in most renal failure patients. The conclusions of these investigators are based on the results of limited hemodynamic manipulations and alterations in the efferent sympathetic limb or the vascular wall were not eliminated. Neither group related the proposed defect to the dialysis blood pressure patterns of their patients. Our studies differ from other investigations relative to type of clinical classification of patients and physiologic dissection of the autonomic nervous system $(5,6,9)$.

Hypertension in chronic renal failure has been investigated previously with respect to measurements of volume (or sodium) and peripheral vein PRA $(1-4,30)$. Elevation of systemic arterial pressure has been attributed primarily to volume excess in most patients with chronic renal disease. It has been proposed that patients who do not experience "normalization" of blood pressure with sufficient volume contraction exhibit PRA measurements which are "inappropriately high" for their volume status $(2-4,30)$. Our patients exhibited blood pressures which did not correlate significantly with volume measurements, but the correlation usually improved via multiple regression analyses of volume and PRA ( Table V). However, patients who exhibited hemodialysis hypotension were noted to have significantly higher blood pressures before and after hemodialysis treatment despite plasma volumes that were smaller after dialysis and PRA measurements that were similar to our other group. Thus, alterations in plasma volume and PRA do not adequately explain the present observations.

To our knowledge, a role for sympathetic nervous system activity in the maintenance of hypertension in patients with chronic renal failure has not been defined. However, adrenergic function has been investigated in a variety of ways in many forms of systemic hypertension $(11,12)$. Biochemical investigations of adrenergic activity in "primary" hypertension have included the measurement of plasma catecholamines and urinary catecholamines or metabolites (31-35). Any potential importance of these observations has been lessened by the recognition of the fact that urinary and plasma concentrations of catecholamines may be influenced by factors other than sympathetic nervous system activity, i.e. alterations of neuronal re-uptake and storage, tissue metabolism, and renal handling may exert profound effects. Any possible contribution of these factors would influence observed catecholamine concentrations even more profoundly in the patient with chronic renal failure.

We believe that the measurement of plasma $\mathrm{D} \beta \mathrm{H}$ activity is better suited for the assessment of adrenergic function (particularly in the uremic patient) than are assays of catecholamine concentration. $\mathrm{D} \beta \mathrm{H}$ is a cate- cholamine-synthesizing enzyme that is released with norepinephrine from the synaptic vesicles of sympathetic nerve terminals; there is no re-uptake, no known route of excretion, and biologic half-life appears to be much longer than that of norepinephrine $(15,35,36)$. Studies of plasma $\mathrm{D} \beta \mathrm{H}$ activity in the rat have demonstrated an increase of enzymatic activity and blood pressure following stress immobilization (37). Furthermore, removal of both adrenal glands does not alter the effect of stress or lower plasma $\mathrm{D} \beta \mathrm{H}$ activity (36), suggesting that $\mathrm{D} \beta \mathrm{H}$ in rat plasma is derived predominately from sympathetic nerve terminals. Thus, it has been proposed that $\mathrm{D} \beta \mathrm{H}$ in plasma may provide a useful index of sympathetic nervous system function in man (12).

The possible implications of differing values for plasma $\mathrm{D} \beta \mathrm{H}$ activity in human subjects has not been established, and alternative explanations for $\mathrm{D} \beta \mathrm{H}$ as an index of adrenergic function have been proposed. The hypotheses include individual variability in the plasma clearance of enzyme protein and differences within the synaptic vesicle of the ratio between soluble $D \beta H$ and catecholamines. These situations have not ben observed in experimental animals $(13,15,36,37)$. A previous investigation, which suggested individual variability in the relationship between enzymatic activity and enzyme protein, has been invalidated (38), and a recent clinical study continues to support the usefulness of plasma $\mathrm{D} \beta \mathrm{H}$ activity as an index of adrenergic function in man (39).

In the present investigation plasma $\mathrm{D} \beta \mathrm{H}$ activity was observed to be significantly greater in patients with frequent hemodialysis hypotension (Fig. 3) than in patients without this abnormality. As noted previously, the hemodialysis hypotensive patients exhibited significantly higher supine MAP than the other group. Furthermore, the higher systemic arterial blood pressures before and after hemodialysis could not be related entirely to PRA or ${ }^{125} \mathrm{I}$-albumin plasma volume, and our results suggest that adrenergic tone as reflected by plasma $\mathrm{D} \beta \mathrm{H}$ activity contributes importantly to the observed MAP. Reasons for this observation are not obvious at the present time, but it is attractive to postulate that patients with hemodialysis hypotension are similar to the experimental animal with neurogenic hypertension after deafferentation of the baroreceptors $(40-42)$. Further investigation of a larger number of similar patients will be required to support this hypothesis.

In conclusion, we have investigated a group of chronic renal failure patients with frequent hemodialysis hypotension and compared them with subjects who rarely exhibit this phenomenon. First, the results of amyl nitrite inhalation and cold pressor test suggest an autonomic nervous system defect which is best localized to the visceral afferent limb of the baroreceptor or cardio- 
pulmonary reflex arcs. Patients with hemodialysis hypotension exhibit pre- and postdialysis hypertension, which does not appear to be related only to volume or the renin-angiotensin system. Finally, the group with hemodialysis hypotension exhibits significantly higher plasma $\mathrm{D} \beta \mathrm{H}$ activity than other dialysis patients without hypotension. The proposed visceral afferent limb defect appears to result in a decreased ability to respond appropriately to the acute hypotensive stimulus of hemodialysis and a decrement in tonic inhibition of the efferent adrenergic system. This situation may be analogous to the experimental animal with labile blood pressure after surgical section of the afferent baroreceptor nerves $(40-42)$.

\section{ACKNOWLEDGMENTS}

We are grateful to Drs. Darrell D. Fanestil and Allen D. Johnson for their advice on the manuscript and to Drs. Clyde H. Beck and Arnold Roland for the use of their patients. Our appreciation is extended to Mrs. Joan Sable, Ms. Rachel Rubin, Mr. Lou Walls, and Mr. David Stackle for their able technical assistance and Mrs. Linda Brandt for her excellent secretarial support.

The studies were supported through grants from the National Institutes of Health (HL-18095) and the Veterans Administration.

\section{REFERENCES}

1. Dustan, H. P., R. C. Tarazi, and E. L. Bravo. 1972. Physiologic characteristics of hypertension. Am. J. Med. 52: 610-622.

2. Schalekamp, M. A., D. G. Beevers, J. D. Briggs, J. J. Brown, D. L. Davies, R. Fraser, M. Lebel, A. F. Lever, A. Medina, J. J. Morton, J. I. S. Robertson, and M. Tree. 1973. Hypertension in chronic renal failure. An abnormal relation between sodium and the reninangiotensin system. Am. J. Med. 55 : 379-390.

3. Bianchi, G., C. Ponticelli, U. Bardi, B. Redaelli, L. Campolo, C. De Ponti, and G. Graziani. 1972. Role of the kidney in "salt and water dependent hypertension" of end-stage renal disease. Clin. Sci. 42: 47-55.

4. Brown, J. J., J. R. Curtis, A. F. Lever, J. I. S. Robertson, H. E. De Wardener, and A. J. Wing. 1969. Plasma renin concentration and the control of blood pressure in patients on maintenance hemodialysis. Nephron. 6: 329349.

5. Kersh, E. S., J. S. Kronfield, A. Unger, R. W. Popper, S. Cantor, and K. Cohn. 1974. Autonomic insufficiency in uremia as a cause of hemodialysis-induced hypotension. N. Engl. J. Med. 290: 650-653.

6. Pickering, T. G., B. Gribbin, and D. O. Oliver. 1972. Baroreflex sensitivity in patients on long-tern haemodialysis. Clin. Sci. (Oxf.). 43: 645-657.

7. Goss, J. E., A. C. Alfrey, J. H. K. Vogel, and J. H. Holmes. 1967. Hemodynamic changes during hemodialysis. Trans. Am. Soc. Artif. Intern. Organs. 13: 6876.

8. Kim, K. E., M. Neff, B. Cohen, M. Somerstein, J. Chinitz, G. Onesti, and C. Swartz. 1970. Blood volume changes and hypotension during hemodialysis. Trans $\mathrm{Am}$. Soc. Artif. Intern. Organs. 16: 508-514.
9. Lazarus, J. M., C. L. Hampers, E. G. Lowrie, and J. P. Merrill. 1973. Baroreceptor activity in normotensive and hypertensive uremic patients. Circulation. 47: 10151021.

10. Thomson, P. D., and K. L. Melmen. 1968. Clinical assessment of autonomic function. Anesthesiology. 29: 724-731.

11. Geffen, L. 1974. Serum dopamine $\beta$-hydroxylase as an index of sympathetic function. Life Sci. 14: 1593-1604.

12. Weinshilboum, R., and J. Axelrod. 1971. Serum dopamine-beta-hydroxylase activity. Circ. Res. 28: 207-315.

13. Gerwitz, G. P., and I. J. Kopin. 1970. Release of dopamine- $\beta$-hydroxylase with norepinephrine during cat splenic nerve stimulation. Nature (Lond.). 227: 406407.

14. De Potter, W. P., A. F. De Schaepdryver, E. J. Moerman, and A. D. Smith. 1969. Evidence for release of vesicle-proteins together with noradrenaline upon stimulation of the splenic nerve. J. Physiol. (Lond.). 204: 102P-104P.

15. Rush, R. A., and L. B. Geffen. 1972. Radioimmunoassay and clearance of circulatory dopamine- $\beta$-hydroxylase. Circ. Res. 31 : 444-452.

16. Stone, R. A., N. Kirshner, J. C. Gunnells, and R. R. Robinson. 1974. Changes of plasma dopamine- $\beta$-hydroxylase activity and other plasma constituents during the cold pressor test. Life Sci. 14: 1797-1805.

17. Bristow, J. D., E. B. Brown, Jr., D. J. C. Cunningham, R. C. Goode, M. G. Howson, and P. Sleight. 1971. The effects of hypercapnia, hypoxia and ventillation on the baroreflex regulation of the pulse interval. J. Physiol. (Lond.). 216: 281-302.

18. Haber, E., T. Koerner, L. B. Page, B. Kliman, and A. Purnode. 1969. Application of a radioimmunoassay for angiotensin I to the physiologic measurements of plasma renin activity in normal human subjects. $J$. Clin. Endocrinol. Metab. 29: 1349-1355.

19. Nagatsu, T., and S. Udenfriend. 1972. Photometric assay of dopamine- $\beta$-hydroxylase activity in human blood. Clin. Chem. 18: 980-983.

20. Stone, R. A., J. C. Gunnells, R. R. Robinson, S. Schanberg, and N. Kirshner. 1974. Dopamine-beta-hydroxylase in primary and secondary hypertension. Circ. Res. Suppl. I. 34 and 35 : I-47-I-56.

21. Bliss, C. I. 1970. Statistics in Biology. McGraw-Hill Book Company, New York.

22. Johnson, R. H., and J. M. K. Spalding. 1974. Disorders of the Autonomic Nervous System. Blackwell Scientific Publications, F. A. Davis Company, Philadelphia, Pa. 1-22.

23. Chalmers, J. P. 1975. Brain amines and models of experimental hypertension. Circ. Res. 36: 469-480.

24. Wooten, G. F., and P. V. Cardon. 1973. Plasma dopamine- $\beta$-hydroxylase activity, evaluation in man during cold pressor test and exercise. Arch. Neurol. 28: 103106.

25. Rockson, S., R. Stone, M. van der Weyden, and W. N. Kelley. 1974. Lesch-Nyhan syndrome: evidence for abnormal adrenergic function. Science (Wash. D. C.). 186: 934-935.

26. Reid, J. L., P. J. Lewis, and C. T. Dollery. 1973. Central and peripheral mechanisms in the maintenance of experimental hypertension in the rabbit. Clin. Sci. Mol. Med. 45: 701-709.

27. Takeshita, A., S. Tanaka, A. Kuroiwa, and M. Nakamura. 1975. Reduced baroreceptor sensitivity in borderline hypertension. Circulation. 51: 738-742. 
28. Wallin, B. G., W. Delius, and K-E. Hagbarth. 1973. Comparison of sympathetic nerve activity in normotensive and hypertensive subjects. Circ. Res. 33: 9-21.

29. Shoukas, A. A., and Kiichi Sagawa. 1973. Control of total systemic vascular capacity by the carotid sinus baroreceptor reflex. Circ. Res. 33: 22-33.

30. Gutkin, M., G. E. Levinson, A. S. King, and N. Lasker. 1969. Plasma renin activity in end-stage kidney disease. Circulation. 40: 563-574.

31. DeQuattro, V., and Y. Miura. 1973. Neurogenic factors in human hypertension: mechanism or myth? Am. J. Med. 55 : 362-378.

32. Nestel, P. J., and M. D. Esler. 1970. Patterns of catecholamine excretion in urine in hypertension. Circ. Res. Suppl. II. 26 and 27: II-75-II-81.

33. Engelman, K., B. Portnoy, and A. Sjoerdsma. 1970. Plasma catecholamine concentrations in patients with hypertension. Circ. Res. Suppl. I. 26 and 27: I-141I-146.

34. Louis, W. J., A. E. Doyle, and S. Anavekar. 1973. Plasma norepinephrine levels in essential hypertension. N. Engl. J. Med. 288: 599-601.

35. Viveros, O. H., L. Arqueros, and N. Kirshner. 1968. Release of catecholamines and dopamine- $\beta$-oxidase from the adrenal medulla. Life Sci. $7: 609-618$.

36. Molinoff, P. B., S. Brimijoin, R. Weinshilboum, and
J. Axelrod. 1970. Neurally mediated increase in dopamine- $\beta$-hydrolyase activity. Proc. Natl. Acad. Sci. U. S. $A .66: 453-458$.

37. Lamprecht, F., R. B. Williams, and I. J. Kopin. 1973. Serum dopamine-beta-hydroxylase during development of immobilization-induced hypertension. Endocrinology. 92: 953-956.

38. Rush, R. A., P. E. Thomas, and S. Udenfriend. 1975. Measurement of human dopamine- $\beta$-hydroxylase in serum by homologous radioimmunoassay. Proc. Natl. Acad. Sci. U. S. A. 72: 750-752.

39. Naftchi, E. N., F. G. Wooten, E. W. Lowman, and J. Axelrod. 1974. Relationship between serum dopamine$\beta$-hydroxylase activity, catecholamine metabolism, and hemodynamic changes during paroxysmal hypertension in quadriplegia. Circ. Res. 35: 850-861.

40. Liedtke, A. J., C. W. Urschel, and E. S. Kirk. 1973. Total systemic autoregulation in the dog and its inhibition by baroreceptor reflexes. Circ. Res. 32: 673-677.

41. DeQuattro, V., T. Nagatsu, R. Maronde, and N. Alexander. 1969. Catecholamine synthesis in rabbits with neurogenic hypertension. Circ. Res. 24: 545-555.

42. Mancia, G., and D. E. Donald. 1975. Demonstration that the atria, ventricles, and lungs are each responsible for a tonic inhibition of the vasometer center in the dog. Circ. Res. 36: 310-318. 